\title{
Amisulpride vs. Risperidone in Chronic Schizophrenia: Results of a 6-month Double-blind Study
}

Daniel Sechter, Joseph Peuskens, Odile Fleurot, Werner Rein, Yves Lecrubier, and the Amisulpride Study Group

This multicenter, double-blind, randomized study evaluated the efficacy, safety and functional effects of two atypical antipsychotics, amisulpride and risperidone, in patients with chronic schizophrenia (DSMIV) with a recent worsening of symptoms. It was planned as a non-inferiority trial. 309 patients received amisulpride (400-1000 mg/day) or risperidone (4-10 $\mathrm{mg} /$ day) for six months. Amisulpride was demonstrated to be not inferior to risperidone with respect to the decrease in Positive and Negative Syndrome Scale (PANSS) total score from baseline (90\% 2-sided confidence interval $(-5.6 ; 4.0))$. Symptomatic improvement measured with the Brief Psychiatry Rating Scale (BPRS), the PANSS positive subscale, and the Bech
Rafaelsen Melancholia Scale was similar in both groups. Amisulpride was significantly $(\mathrm{p}<.05)$ superior to risperidone in terms of response $(\geqslant 50 \%$ improvement in PANSS and BPRS total scores or "very much/much improved" on the Clinical Global Impression Scale) and also demonstrated better functional effects and subjective response. Both treatments were well tolerated and had a similar low incidence of extrapyramidal symptoms; however, amisulpride was associated with less weight gain and endocrine/sexual symptoms.

[Neuropsychopharmacology 27:1071-1081, 2002] (C) 2002 American College of Neuropsychopharmacology. Published by Elsevier Science Inc.
KEY WORDS: Antipsychotic; Schizophrenia; Amisulpride; Atypical antipsychotic; Risperidone

Schizophrenia is a chronic and disabling disorder with a lifetime prevalence of approximately $1 \%$ (American

From the Department of Psychiatry, Saint-Jacques Hospital, 2 Place Saint-Jacques, 25030 Besançon cédex, France (DS), Universitair centrum Sint Jozef, Leuvensesteenweg 517, 3070 Kortenberg, Belgium (JP), Sanofi-Synthelabo Research, 1 avenue Pierre Brossolette, 91385 Chilly Mazarin cédex, France (OF, WR), and INSERM, Unité 302, Pavillon Clérambault, Salpétrière Hospital, 47 boulevard de l'Hôpital, 75013 Paris, France (YL).

Address correspondence to: Daniel Sechter, Department of Psychiatry, Saint-Jacques Hospital, 2 Place Saint-Jacques, 25030 Besançon cédex, France. Tel.: 33.3.81.21.81.52; Fax: 33.3.81.21.88.17; E-mail: daniel.sechter@ufc-chu.univ-fcomte.fr

Received August 22, 2001; revised April 25, 2002; accepted May 22, 2002.

Online publication: 5/23/02 at www.acnp.org/citations/Npp052302311/ default.htm.
Psychiatric Association 1994). It results in significant long-term functional handicap, severely impairs the quality of life of both the patient and the caregivers and places a considerable financial burden on society.

The clinical efficacy of amisulpride against acute psychotic symptoms at high doses (400-800 mg/day) and prominent negative symptoms at low doses (50$300 \mathrm{mg} /$ day) may be explained by its preferential affinity for pre-synaptic dopaminergic $\mathrm{D}_{2}$ and $\mathrm{D}_{3}$ autoreceptor subtypes at low doses, while higher doses result in predominant antagonism of post-synaptic dopamine receptors (Perrault et al. 1997; Schoemaker et al. 1997). It also shows selectivity for dopamine receptors in limbic and hippocampal structures, rather than striatal structures, thus suggesting a lower propensity to induce extrapyramidal effects than seen with the classical antipsychotics (Perrault et al. 1997). Studies in 
patients with acute exacerbations of schizophrenia have shown that amisulpride is as effective as haloperidol and flupenthixol in treating positive symptoms (Möller et al. 1997; Puech et al. 1998; Wetzel et al. 1998) with additional effects on negative symptoms compared with haloperidol (Möller et al. 1997). Amisulpride significantly reduces negative symptoms in patients with chronic schizophrenia presenting with enduring predominant negative symptoms (Boyer et al. 1995; Loo et al. 1997; Danion et al. 1999) and in neuroleptic naive mainly negative schizophrenics at the onset of the disorder (Paillère-Martinot et al. 1995). The efficacy of amisulpride was maintained in an open long-term study, with a clear advantage over haloperidol in terms of safety and efficacy (Colonna et al. 2000). This advantage over a standard neuroleptic was also demonstrated when social adjustment and quality of life were taken into account (Colonna et al. 2000; Carrière et al. 2000). In all these trials, amisulpride constantly demonstrated a good safety and tolerability profile, with fewer extrapyramidal symptoms than typical neuroleptics and a low incidence of weight gain and endocrine side-effects (Coulouvrat and DondeyNouvel 1999).

In contrast to amisulpride, risperidone, another atypical antipsychotic, is a central 5- $\mathrm{HT}_{2}$ and dopamine $\mathrm{D}_{2}-$ receptor antagonist at all doses, with a relatively higher affinity for $5-\mathrm{HT}_{2}$ receptors. It also possesses some short-acting norepinephrine receptor antagonist activity, as well as some antihistaminergic activity (Leysen et al. 1988; Janssen et al. 1988). Studies have shown that it is at least as effective as the typical neuroleptics in patients with acute and chronic schizophrenia with positive and/or negative symptoms (Chouinard et al. 1993; Hoyberg et al. 1993; Marder and Meibach 1994; Carman et al. 1995; Huttunen et al. 1995; Peuskens and the Risperidone Study Group 1995) and that it is better tolerated than typical neuroleptics in terms of extrapyramidal side effects (Geddes et al. 2000).

There is increasing interest in comparative data on atypical antipsychotics to optimize their clinical use. Up to now, amisulpride has been compared with other antipsychotics in an exhaustive meta-analysis (Leucht et al. 2002), but head-to-head comparisons are preferable to allow more specific comparative information.

An earlier short-term double-blind study in patients with acute exacerbations of schizophrenia showed that amisulpride was as effective as risperidone in treating positive symptoms and showed a trend toward greater improvement in negative symptoms; moreover, amisulpride was associated with significantly less weight gain than risperidone (Peuskens et al. 1999).

A controlled long-term study was therefore needed to assess whether these findings were stable with time and impacted on functional and subjective adaptation of the patients.

\section{METHODS}

\section{Design}

This study was a 6-month, multicenter, double-blind, randomized, controlled trial in schizophrenics (DSM IV, American Psychiatric Association 1994) with a recent worsening of their clinical state comparing the therapeutic effects of amisulpride $400-1000 \mathrm{mg} /$ day to those of risperidone $4-10 \mathrm{mg} /$ day. The doses chosen correspond to the efficacious dosings established for both compounds. The study was conducted in 51 psychiatric centers in Austria, Belgium, Estonia, France, Germany, Hungary, Latvia, The Netherlands, and Slovenia.

\section{Study Population}

Male or female in- or out-patients (aged 18-65 years) with chronic schizophrenia (disease duration of at least two years) of the paranoid, disorganized, undifferentiated, or residual type (DSM-IV) were eligible for the study. The patients were required to have a Positive and Negative Syndrome Scale (PANSS, Kay et al. 1987) total score between 60 and 120 and their clinical state had to show a recent deterioration needing a change in treatment. Patients were excluded if: (1) they had predominant negative symptoms ( 3 or more items $\geqslant 4$ on the negative PANSS subscale and less than 3 items $\geqslant 4$ on the positive PANSS); (2) if they had symptoms of substance-related withdrawal; (3) if they presented a cardiovascular disease, severe respiratory, hematologic or endocrinologic diseases, Parkinson's disease, phaeochromocytoma, significant abnormal laboratory tests, or a history of allergy or hypersensitivity to risperidone or benzamides; (4) if they were currently receiving amisulpride or risperidone; (5) if they had shown no response to at least two well-validated antipsychotics; (6) if they had received lithium-based therapy in the previous 10 days; or (7) if they had received long-acting antipsychotics (if the usual interval between two injections had not elapsed before inclusion). Pregnant or breastfeeding women and women of childbearing age not using adequate contraception were also excluded.

The study was approved by the local ethics committee and/or the institutional review board of the participating centers/countries according to local legislation and was conducted in accordance with Good Clinical Practice guidelines and the Declaration of Helsinki (Helsinki 1964) and subsequent revisions. All patients gave written informed consent before the start of the study.

\section{Treatment}

The study started with a 6-day single-blind placebo washout period which could be reduced to two days in case of aggravation of psychotic symptoms. Hospital- 
ization was recommended during this phase. Patients who showed a placebo response, defined as an improvement of at least $20 \%$ on the PANSS total score during this phase, were not eligible for further investigation. The patients then entered a 6-month, double blind phase during which they were randomized to receive amisulpride (400-1000 mg/day) or risperidone (4-10 mg/day). The dose of risperidone was titrated up from 1 to $4 \mathrm{mg}$ /day over the first four days; this dose was maintained until the end of the first week. Amisulpride was started at $400 \mathrm{mg} /$ day on day 1 and then kept stable from day 2 at $600 \mathrm{mg} /$ day for the first week. The doses were initially set at a ratio of $1 \mathrm{mg}$ risperidone to $100 \mathrm{mg}$ amisulpride according to the range of efficacious doses of both compounds; they were then adjusted according to the Clinical Global Impression scale (CGI) item 3 (efficacy index, National Institute of Mental Health 1976a). Biperiden was allowed to control extrapyramidal symptoms.

Benzodiazepines prescribed for at least 14 days prior to the screening visit could be continued throughout the study. Patients presenting with anxiety at inclusion were allowed diazepam (up to $40 \mathrm{mg}$ /day) during the first week of the double-blind phase. After this period, a dose of no more than $30 \mathrm{mg} /$ day was permitted for no more than 4 weeks up to day 56. Minimal use of zolpidem $(\leqslant 10 \mathrm{mg} /$ day) or zopiclone $(\leqslant 7.5 \mathrm{mg} /$ day) was permitted in case of insomnia, but could not be prescribed for more than one month.

No other psychotropic medications were permitted during the study.

\section{Assessments}

The primary efficacy criterion was the PANSS total score absolute change from baseline. Secondary efficacy criteria included the PANSS negative, positive and global psychopathology scores, the Brief Psychiatric Rating Scale (BPRS) total score extracted from the PANSS (Bell et al. 1992), the Scale for the Assessment of Negative Symptoms (SANS) (Andreasen 1983) total score, the Bech Rafaelsen Melancholia Scale (BRMS) (Bech and Rafaelsen 1990) for evaluating the severity of depression, the CGI severity of illness and global improvement scales (National Institute of Mental Health 1976a), the Social and Occupational Functioning Assessment Scale (SOFAS) (American Psychiatric Association 1994) for evaluating the level of social and occupational functioning and a scale designed to measure the subjective response to treatment (Van Putten and May 1978; Hogan and Awad 1992).

Safety was assessed by reporting of adverse events, physical examination, vital signs, body weight, laboratory parameters and the following neurological scales: the Simpson Angus Scale (Simpson and Angus 1970) for parkinsonism, the Barnes Akathisia Scale (Barnes
1989) and the Abnormal Involuntary Movement Scale (AIMS) (National Institute of Mental Health 1976b) for dyskinesia.

The PANSS was rated during the wash-out phase (day -6), at baseline (day 1) and after 1, 2, 3, 4, 6, and 8 weeks and 3, 4, 5, and 6 months; the CGI was measured in parallel with the exception of day -6 . The SANS, BRMS and SOFAS were assessed at baseline and after 8 weeks and 6 months; the subjective response was determined after 1 week, 8 weeks, and 6 months. Physical examination, vital signs, body weight, the Simpson Angus scale and the Barnes Akathisia Scale were performed during the wash-out phase, at baseline and after 1, 2, 3, 4, 6, and 8 weeks, then monthly; adverse events were monitored at all visits except day -6 . The AIMS was performed during washout, at baseline, and after 8 weeks and 6 months. Laboratory parameters were measured during washout and at 6 months.

Assessments were performed by the investigators who had participated in a videotape training session.

\section{Statistical Analysis}

The main goal of this study was to assess whether the therapeutic advantages observed during a short-term period were maintained and relevant on the long-term. Therefore, all efficacy analyses are presented on the "maintenance" population (patients exposed to treatment for more than two months, with at least one evaluation after that period). Analyses of the primary endpoint on the intent-to-treat (ITT) overall population (all patients exposed to treatment and with at least one evaluation after baseline) and on the completer population (patients from the ITT population who completed all evaluations up to six months) will also be presented. Safety was assessed in all patients exposed to treatment.

The primary efficacy variable, the PANSS total score absolute change from baseline, was analyzed according to a non-inferiority hypothesis; non-inferiority was considered confirmed if the $90 \%$ 2-sided confidence interval calculated for the difference risperidone minus amisulpride had an upper limit less than 8 points, corresponding to the non-inferiority margin defined in the protocol. For the BPRS total score, first a superiority test was done and, if the null hypothesis was not rejected, a secondary non-inferiority hypothesis was tested with a non-inferiority limit set at six points considered clinically relevant with regards to the placebo-active drug difference generally observed (Chouinard et al. 1993; Marder and Meibach 1994; Beasley et al. 1996a,b; Van Kammen et al. 1996; Arvanitis et al. 1997; Small et al. 1997; Zimbroff et al. 1997; Peuskens et al. 1999). All other efficacy parameters were analyzed using 2-sided tests for superiority. The global $\alpha$-risk for each hypothesis was .05; continuous variables were analyzed using ANOVA, nonordered categorical variables using a Pearson Chi- 
Table 1. Baseline Demographic and Disease Characteristics (Exposed Population)

\begin{tabular}{|c|c|c|c|c|c|c|}
\hline Characteristics & $\begin{array}{c}\text { Amisulpride } \\
(\mathrm{n}=152) \\
\text { Mean (S.D.) }\end{array}$ & $\begin{array}{c}\text { Risperidone } \\
(\mathrm{n}=158) \\
\text { Mean (S.D.) }\end{array}$ & $\begin{array}{c}\text { Total } \\
(\mathrm{n}=310) \\
\text { Mean (S.D.) }\end{array}$ & $\mathbf{F}$ & Df & $p$ \\
\hline Age (years) & $38.4(11.0)$ & $38.4(10.7)$ & $38.4(10.8)$ & 0.00 & 1,308 & 0.98 \\
\hline Weight (kg) & $71.4(14.5)$ & $71.3(13.5)$ & $71.3(14.0)$ & 0.00 & 1,307 & 0.99 \\
\hline Height $(\mathrm{cm})$ & $169.6(8.8)$ & $170.3(9.6)$ & $170.0(9.2)$ & 0.37 & 1,308 & 0.55 \\
\hline \multirow[t]{2}{*}{ Duration of illness (years) } & $11.7(9.1)$ & $11.8(8.6)$ & $11.8(8.9)$ & 0.01 & 1,308 & 0.91 \\
\hline & n (\%) & n (\%) & n (\%) & & & \\
\hline Ethnic origin $^{\mathrm{a}}$ & & & & -- & 1 & 0.36 \\
\hline Caucasian & $144(95)$ & $153(97)$ & $297(96)$ & & & \\
\hline Other & $8(5)$ & $5(3)$ & $13(4)$ & & & \\
\hline $\operatorname{Sex}^{\mathrm{a}}$ & & & & -- & 1 & 0.94 \\
\hline Male & $83(55)$ & $87(55)$ & $170(55)$ & & & \\
\hline Female & $69(45)$ & $71(45)$ & $140(45)$ & & & \\
\hline Type of schizophrenia ${ }^{a}$ & & & & -- & 3 & 0.65 \\
\hline Disorganized & $16(11)$ & $21(14)$ & $37(12)$ & & & \\
\hline Paranoid & $116(76)$ & $111(70)$ & $227(73)$ & & & \\
\hline Undifferentiated & $11(7)$ & $16(10)$ & $27(8)$ & & & \\
\hline Residual & $9(6)$ & $10(6)$ & $19(6)$ & & & \\
\hline Hospitalization $^{\mathrm{b}}$ & & & & -- & 3 & 0.64 \\
\hline Out-patients & $33(22)$ & $33(21)$ & $66(21)$ & & & \\
\hline In-patients & $115(76)$ & $116(73)$ & $231(75)$ & & & \\
\hline In-day hospital & $3(2)$ & $7(4)$ & $10(3)$ & & & \\
\hline Other & $1(1)$ & $2(1)$ & $3(1)$ & & & \\
\hline
\end{tabular}

${ }^{a}$ Chi-square test

${ }^{\mathrm{b}}$ Fisher exact test

square test and ordered variables using a Cochran-Mantel-Haenszel test. The Kruskal-Wallis ANOVA or Fisher Exact test were used for non-parametric analyses, when relevant, (ie, for qualitative data when at least one expected cell frequency was less than 5 and for quantitative data when normality of the distribution was significantly rejected with the Shapiro-Wilk test). Kaplan-Meier survival estimates in each group were used to describe across time proportions of patients who maintained response, i.e. PANSS improvement $\geqslant 40 \%$ versus baseline in the subgroup of patients who had already achieved this response criterion at two months in the maintenance population. Comparison was performed between treat- ment groups using the log-rank test. Analyses of adverse events and laboratory parameters were descriptive. Statistical comparisons were performed for vital signs, body weight and the three neurological scales.

Based on the results of a previous short-term (8 weeks) comparison between risperidone and haloperidol (Peuskens et al. 1995), and taking into account the $45 \%$ dropout rate in an amisulpride long-term (12 months) open comparison versus haloperidol (Colonna et al. 2000), the total sample size to be included for noninferiority testing in the study was 300. Analyses were performed using SAS software 6.09 (SAS Institute Inc., Cary, NC). Because of the high number of centers (51)

Table 2. Summary of Premature Withdrawals from the Study (Exposed Population)

\begin{tabular}{|c|c|c|c|c|}
\hline & $\begin{array}{c}\text { Amisulpride }(\mathrm{n}=152) \\
\mathrm{n}(\%)\end{array}$ & $\begin{array}{c}\text { Risperidone }(n=158) \\
n(\%)\end{array}$ & Df & $p$ \\
\hline Distribution of end of study ${ }^{a}$ & & & 1 & 0.143 \\
\hline Normal terminations & $98(64)$ & $89(56)$ & & \\
\hline Total premature withdrawals & $54(36)$ & $69(44)$ & & \\
\hline \multicolumn{5}{|l|}{ Reasons for withdrawal } \\
\hline Lost to follow-up & $3(2)$ & $5(3)$ & & \\
\hline Lack of efficacy & $11(7)$ & $18(11)$ & & \\
\hline Adverse event & $21(14)$ & $20(13)$ & & \\
\hline Uncooperative & $6(4)$ & $6(4)$ & & \\
\hline Recovery & $1(1)$ & $1(1)$ & & \\
\hline Other & $12(8)$ & $19(12)$ & & \\
\hline
\end{tabular}

${ }^{a}$ Chi-square test 
allocated in nine countries, a center effect was not included in the statistical model.

\section{RESULTS}

A total of 310 patients were randomized and exposed to treatment (152 to amisulpride and 158 to risperidone) between May 1997 and February 2000. There were no statistically significant differences between the groups in terms of demographic or disease characteristics (Table 1). The duration of illness (almost 12 years) and the proportion of patients hospitalized at the beginning of the study $(78 \%)$ indicated a fairly severe population. The ITT overall population consisted of 309 patients (152 amisulpride and 157 risperidone, one patient being lost to follow-up during the first treatment week) and the "maintenance" population was of 244 patients (121 amisulpride and 123 risperidone).

Premature withdrawals during the 6-month period were comparable between groups, both quantitatively and qualitatively (Table 2). Overall, 98 amisulpride and 89 risperidone patients (i.e. $60 \%$ of the randomized population) completed the 6-month study.

The mean dose with the longest exposure was $683 \pm$ $204 \mathrm{mg} /$ day in the amisulpride group and $6.92 \pm 2.14$ $\mathrm{mg} /$ day in the risperidone group. The dosing strategy was therefore very similar in the two groups.

\section{Efficacy}

Except where stated, efficacy data are presented using the "maintenance" population and the last-observationcarried forward (LOCF) procedure (all other analyses yielded similar results).
Amisulpride was demonstrated to be not inferior to risperidone with respect to the primary efficacy parameter. The PANSS total score decreased markedly in both groups (from $91.1 \pm 13.0$ at baseline to $58.9 \pm 22.6$ after six months in the amisulpride group and from $92.5 \pm$ 12.2 to $61.1 \pm 20.9$ in the risperidone group) (Figure 1). The non-inferiority analysis showed that the decrease in the PANSS total score from baseline was not inferior with amisulpride as compared with risperidone $(90 \%$ 2 -sided confidence interval $(-5.6 ; 4.0))$. The 2 -sided $95 \%$ confidence interval also confirms the non-inferiority of amisulpride compared with risperidone (Table 3). Similar results were observed in the ITT overall population (90\% 2-sided confidence interval $(-5.4 ; 3.7)$ ).

Both amisulpride and risperidone also resulted in marked improvements in the BPRS total score $(-19.8$ vs. -19.6 , respectively), the CGI severity of illness score $(-1.7$ vs. -1.5$)$, the PANSS positive subscore $(-11.8$ vs. -12.1$)$, PANSS global psychopathology score $(-15.3$ vs. -15.4$)$, the SANS total score $(-14.8$ vs. -12.1$)$, and the BRMS ( -4.9 vs. -3.9$)$, with no significant differences between treatments (Table 3 ). The improvement in the PANSS negative subscore (Table 3) did not reach statistical significance $(-5.1$ for amisulpride vs. -3.9 for risperidone; $\mathrm{F}=2.90 ; \mathrm{df}=1,242 ; p=.09)$. When the change in the BPRS total score was analyzed using a non-inferiority limit of six points, the results showed that the mean BPRS total score decrease in the amisulpride group was not inferior to that in the risperidone group ( $90 \%$ 2-sided confidence interval $(-3.1 ; 2.7))$. The 2 -sided $95 \%$ confidence interval again confirmed the non-inferiority of amisulpride compared with risperidone (Table 3). Similar results were observed in the ITT overall population (90\% 2-sided confidence interval $(-3.1 ; 2.5)$ ).

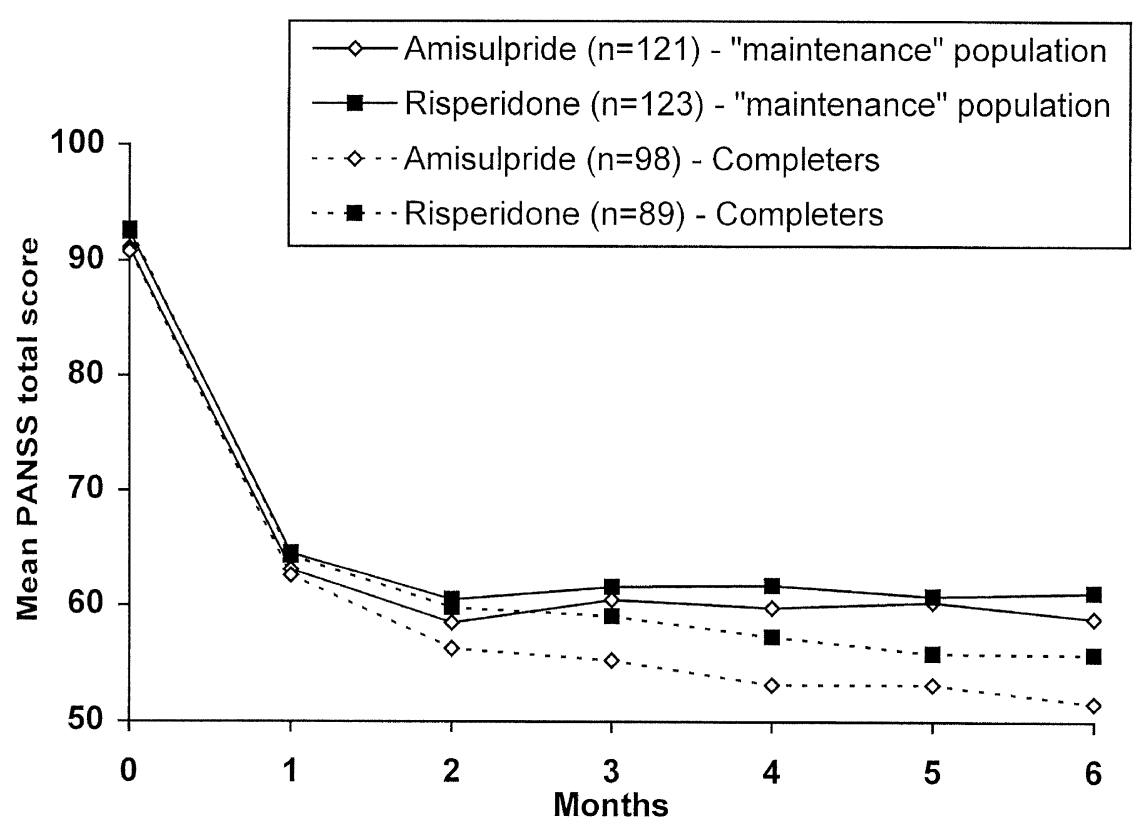

Figure 1. PANSS total score absolute change from baseline: "maintenance" and completer populations (LOCF). 


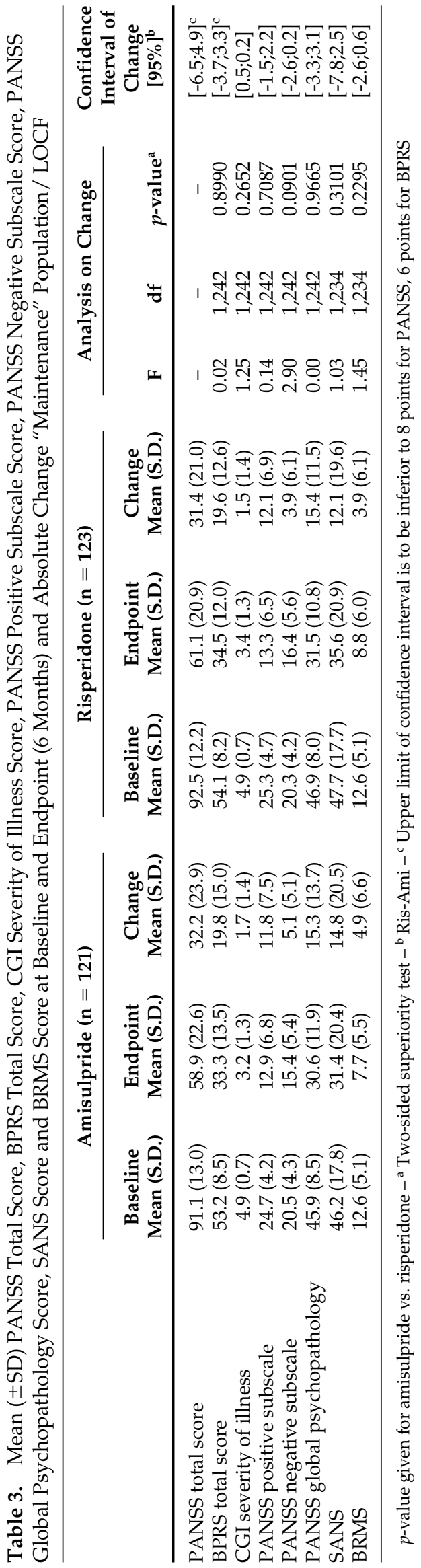

Statistically significant differences between treatments were observed for response rates when using a high threshold for improvement (Table 4). The response rates at the end of the study were significantly higher with amisulpride than with risperidone as assessed by the PANSS total score $(\geqslant 50 \%$ improvement in $65.3 \%$ of amisulpride and $52.0 \%$ of risperidone patients: $\chi^{2}$ test $=$ $4.419 ; \mathrm{df}=1 ; p=.036)$, the BPRS total score $(\geqslant 50 \%$ improvement in $71.9 \%$ of amisulpride and $57.7 \%$ of risperidone patients: $\chi^{2}$ test $\left.=5.372 ; \mathrm{df}=1 ; p=.020\right)$ and the CGI improvement score $(76.9 \%$ of amisulpride and $65.0 \%$ of risperidone patients were very much or much improved: $\chi^{2}$ test $=4.130 ; \mathrm{df}=1 ; p=.042$ ).

\section{Maintenance of Effect}

A subpopulation of patients having responded (PANSS improvement of at least $40 \%$ of baseline) after two months of treatment (92/121 in the amisulpride and 81/123 in the risperidone group, corresponding to $76.7 \%$ and $65.9 \%$ of the "maintenance" population) was identified. A conservative estimation of maintenance of effect, considering all discontinuations and the lack of maintenance as a treatment failure, showed that $65 \%(70 / 92)$ of the amisulpride responders maintained efficacy compared with $57 \%(52 / 81)$ of the risperidone responders; this difference did not reach statistical significance $\left(\chi^{2}\right.$ test $=$ 2.929; $\mathrm{df}=1 ; p=.087$ ).

Kaplan-Meier survival estimates performed in the subgroup of patients from the maintenance population with PANSS improvement $\geqslant 40 \%$ versus baseline at two months showed that patients maintained this level of improvement to a similar extent in both treatment groups $\left(\right.$ Log-rank $\chi^{2}$ test $\left.=1.846 ; \mathrm{df}=1 ; p=.1742\right)($ Figure 2$)$.

\section{Functional Effects and Subjective Response to Treatment}

Amisulpride-treated patients also demonstrated better functional improvement than those given risperidone. The SOFAS score was improved from $46.7 \pm 11.2$ at baseline to $61.2 \pm 17.6$ at six months in the amisulpride group and from $45.9 \pm 12.0$ to $57.8 \pm 17.0$ in the risperidone group $(\mathrm{F}=1.49 ; \mathrm{df}=1,234 ; p=.2228)$. The percentage of SOFAS responders $(\geqslant 50 \%$ increase from baseline) did not show a difference between treatment groups $\left(\chi^{2}\right.$ test $\left.=2.753 ; \mathrm{df}=1 ; p=.097, \mathrm{~ns}\right)$ at six months, with $33 \%$ in the amisulpride group compared with $23 \%$ in the risperidone group (Figure 3). Less severe cut-off limits yielded the following results: $38 \%$ vs. $31 \%$ of responders for a $40 \%$ increase from baseline for amisulpride and risperidone, respectively $\left(\chi^{2}\right.$ test $=$ $1.299 ; \mathrm{df}=1 ; p=.254, \mathrm{~ns})$; when a $30 \%$ improvement cut-off limit was taken into account, the responder rate was significantly superior with amisulpride compared with risperidone, $49 \%$ vs. $35 \%$, $\left(\chi^{2}\right.$ test $=4.545 ; \mathrm{df}=1 ; p<$ 
Table 4. Response Rates after 6 Months for the PANSS Total Score, BPRS Total Score (at $\geqslant 30 \%, \geqslant 40 \%$ and $\geqslant 50 \%$ Improvement from Baseline) and for the CGI Improvement Score (Patients "Very Much or Much Improved"): "Maintenance" Population (LOCF)

\begin{tabular}{|c|c|c|c|c|c|c|c|}
\hline & \multicolumn{2}{|c|}{ Amisulpride $(n=121)$} & \multicolumn{2}{|c|}{ Risperidone $(n=123)$} & \multicolumn{3}{|c|}{ Analysis $^{a}$} \\
\hline & $\mathbf{n}$ & $\%$ & $\mathbf{n}$ & $\%$ & Test & Df & $p$ \\
\hline \multicolumn{8}{|l|}{ PANSS } \\
\hline$\geqslant 30 \%$ & 97 & 80.2 & 94 & 76.4 & 0.502 & 1 & 0.478 \\
\hline$\geqslant 40 \%$ & 87 & 71.9 & 79 & 64.2 & 1.651 & 1 & 0.199 \\
\hline$\geqslant 50 \%$ & 79 & 65.3 & 64 & 52.0 & 4.419 & 1 & 0.036 \\
\hline \multicolumn{8}{|l|}{ BPRS } \\
\hline$\geqslant 30 \%$ & 97 & 80.2 & 100 & 81.3 & 0.051 & 1 & 0.822 \\
\hline$\geqslant 40 \%$ & 95 & 78.5 & 87 & 70.7 & 1.948 & 1 & 0.162 \\
\hline$\geqslant 50 \%$ & 87 & 71.9 & 71 & 57.7 & 5.372 & 1 & 0.020 \\
\hline \multicolumn{8}{|l|}{ CGI } \\
\hline "Very much or much improved" & 93 & 76.9 & 80 & 65.0 & 4.130 & 1 & 0.042 \\
\hline
\end{tabular}

${ }^{\text {a }}$ Chi-square test

.033) (Figure 3). Moreover, significantly more amisulpride-treated patients $(93 \%)$ expressed a positive subjective response to treatment after six months compared with $83 \%\left(\chi^{2}\right.$ test $\left.=5.877 ; \mathrm{df}=1 ; p=.015\right)$ in the risperidone group (Figure 3 ).

\section{Safety and Tolerability}

Amisulpride and risperidone were both well tolerated. There were no differences in the overall incidence of adverse events between the two treatment groups; 111/ 152 patients (73\%) in the amisulpride group and 123/ $158(78 \%)$ in the risperidone group reported at least one adverse event. The adverse events reported by at least $5 \%$ of patients in either group are shown in Table 5. Antiparkinsonian medication was initiated during the study and taken at least once by 36/152 (24\%) patients receiving amisulpride and $47 / 158(30 \%)$ taking risperidone $\left(\chi^{2}\right.$ test $\left.=1.452 ; \mathrm{df}=1 ; p=.228, \mathrm{~ns}\right)$. Specific endocrinological and sexual disorders were reported in one patient $(0.7 \%)$ in the amisulpride group (amenor- rhea) compared with $9(5.7 \%)$ in the risperidone group: three cases of ejaculation failure, three cases of impotence and one amenorrhea, one breast pain and one nonpuerperal lactation (the last three in women). There was also a difference between the treatments with regard to changes in body weight. Patients receiving risperidone experienced a greater increase in mean body weight than those receiving amisulpride; the difference was significant after two months $(1.4$ vs. $0.6 \mathrm{~kg}$; KruskalWallis test $=4.9400 ; \mathrm{df}=1 ; p=.0262)$, but not at six months (2.1 vs. $1.3 \mathrm{~kg}$; Kruskal-Wallis test $=1.9423$; $\mathrm{df}=$ $1 ; p=.1634, \mathrm{~ns})$. During the 6-month period, significantly less amisulpride treated patients presented a weight increase $\geqslant 7 \%$ of that of baseline compared with those receiving risperidone (observed cases, $18 \%(18 / 100)$ versus $34 \%(32 / 95)\left(\chi^{2}\right.$ test $\left.\left.=6.510 ; \mathrm{df}=2 ; p<.05\right)\right)$.

The scores on the Simpson Angus scale, Barnes Akathisia scale, and the AIMS were low at baseline and decreased slightly, but not significantly, during the study (Table 6). There were no statistically significant differences between amisulpride and risperidone at any monthly visit.

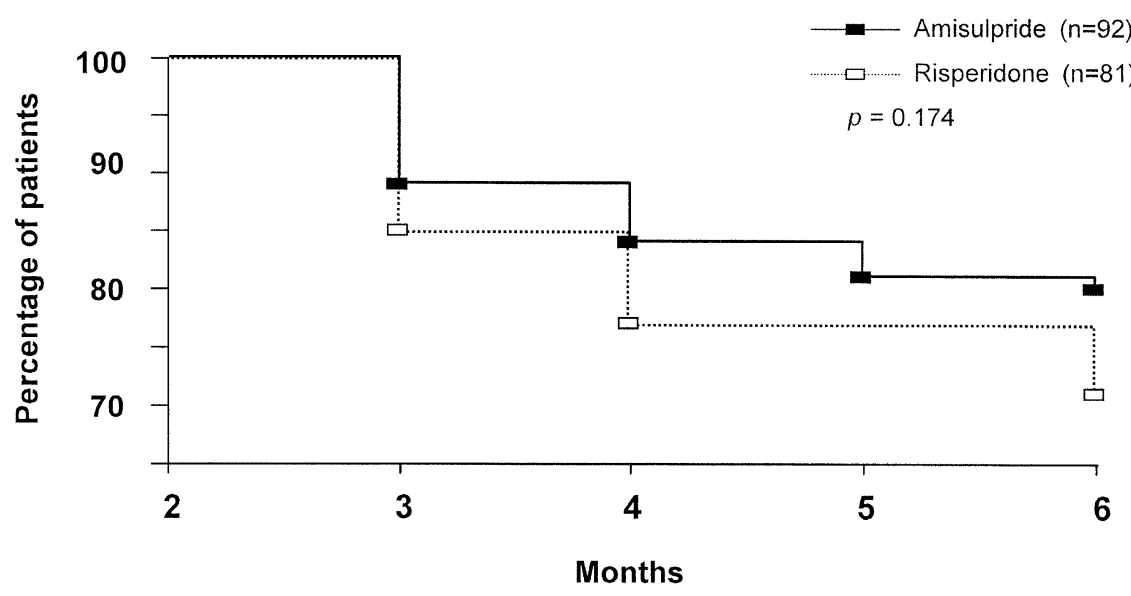

Figure 2. Kaplan-Meier survival curves showing time maintaining response based on the PANSS total score in the patients achieving response criteria (improvement $\geqslant 40 \%$ versus baseline) at two months (LOCF). 


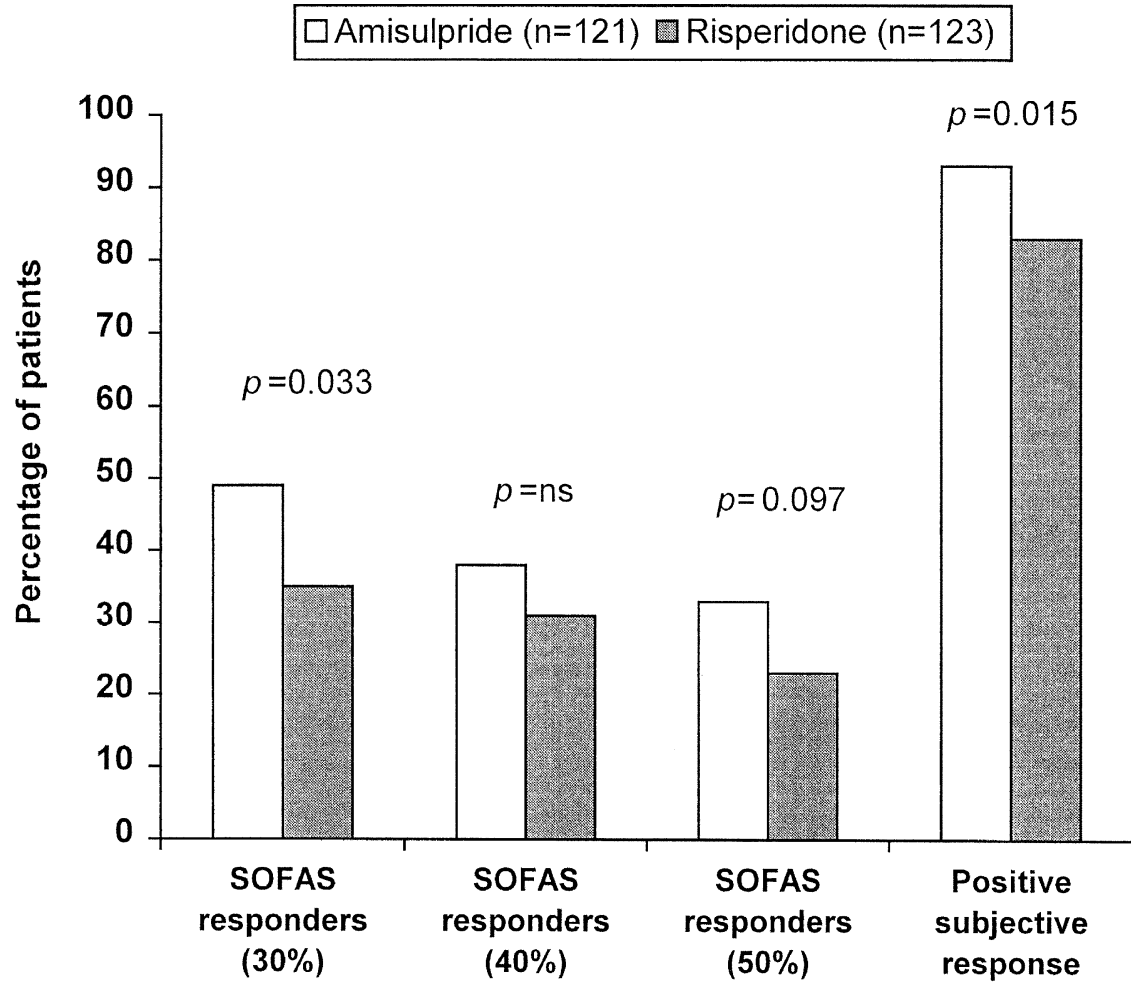

Figure 3. Response rates after six months for the SOFAS score $(\geqslant 30 \%, \geqslant 40 \%$, and $\geqslant 50 \%$ improvement from baseline) and patients positive subjective response: "maintenance" population (LOCF).

There were no clinically relevant changes in vital signs or laboratory parameters in either group.

\section{DISCUSSION}

This study was aimed to show, on over 300 highly symptomatic schizophrenic patients, whether the therapeutic benefit observed during a short-term period was maintained after a 6-month treatment period. The decrease in the PANSS total score with amisulpride was not inferior to that with risperidone; symptomatic improvement measured with the BPRS, the PANSS positive subscale and the BRMS was also similar in both groups. The greater improvement in negative symptoms with amisulpride (PANSS negative subscale) did not reach statistical significance. Using a high threshold for improvement ( $\geqslant 50 \%$ improvement), higher response rates were reported with amisulpride than with risperidone, $65 \%$ vs. $52 \%$ on the PANSS total score and $72 \%$ vs. $58 \%$ on the BPRS total score. The proportion of patients "very much/ much improved" on the CGI improvement scale was also higher with amisulpride, $77 \%$ versus risperidone, $65 \%$.

At the start of the study, patients were also suffering from severe impairment in their social functioning as demonstrated by their low SOFAS scores. Functioning was much improved with both amisulpride and risperidone. When a cut-off improvement of $30 \%$ was taken into account, the responders rate was significantly superior with amisulpride compared with risperidone (49\% vs. 35\%). In addition, significantly more amisulpride-treated patients expressed a positive response to

Table 5. Adverse Events Reported by at least 5\% of Patients in Either Group (Exposed Population)

\begin{tabular}{lcc}
\hline & Amisulpride (n = 152) & Risperidone (n = 158) \\
\hline Hyperkinesia & $29(19.1 \%)$ & $22(13.9 \%)$ \\
Extrapyramidal disorder & & \\
$\quad$ (not otherwise specified) & $18(11.8 \%)$ & $27(17.1 \%)$ \\
Insomnia & $17(11.2 \%)$ & $14(8.9 \%)$ \\
Weight increase & $15(9.9 \%)$ & $18(11.4 \%)$ \\
Psychosis & $15(9.9 \%)$ & $14(8.9 \%)$ \\
Agitation & $14(9.2 \%)$ & $12(7.6 \%)$ \\
Anxiety & $13(8.6 \%)$ & $10(6.3 \%)$ \\
Somnolence & $8(5.3 \%)$ & $12(7.6 \%)$ \\
Depression & $3(2.0 \%)$ & $10(6.3 \%)$ \\
\hline
\end{tabular}


Table 6. Neurological Scale Scores (Exposed Population; LOCF)

\begin{tabular}{|c|c|c|c|c|c|c|c|c|c|}
\hline & \multicolumn{3}{|c|}{ Amisulpride $(\mathrm{n}=152)$} & \multicolumn{3}{|c|}{ Risperidone ( $n=158$ ) } & \multirow{2}{*}{\multicolumn{3}{|c|}{ Analysis on change }} \\
\hline & \multirow{2}{*}{$\begin{array}{c}\text { Baseline } \\
\text { Mean (S.D.) }\end{array}$} & \multirow{2}{*}{$\begin{array}{c}\text { Endpoint } \\
\text { Mean (S.D.) }\end{array}$} & \multirow{2}{*}{$\begin{array}{c}\text { Change } \\
\text { Mean (S.D.) }\end{array}$} & \multirow{2}{*}{$\begin{array}{c}\text { Baseline } \\
\text { Mean (S.D.) }\end{array}$} & \multirow{2}{*}{$\begin{array}{c}\text { Endpoint } \\
\text { Mean (S.D.) }\end{array}$} & \multirow{2}{*}{$\begin{array}{c}\text { Change } \\
\text { Mean (S.D.) }\end{array}$} & & & \\
\hline & & & & & & & $\Pi^{2}$ & df & $p$-value \\
\hline Simpson Angus ${ }^{a}$ & $0.33(0.45)$ & $0.24(0.34)$ & $0.10(0.45)$ & $0.34(0.43)$ & $0.27(0.37)$ & $0.07(0.41)$ & 0.06 & 1 & 0.8122 \\
\hline \multirow[t]{2}{*}{ AIMS $^{a}$} & $1.71(3.52)$ & $1.59(3.22)$ & $0.16(3.17)$ & $1.80(3.82)$ & $1.70(3.78)$ & $0.10(4.10)$ & 0.01 & 1 & 0.9207 \\
\hline & n (\%) & n (\%) & & n (\%) & n (\%) & & & & \\
\hline Barnes Akathisia ${ }^{b}$ & & & & & & & 2.34 & 1 & 0.126 \\
\hline Absent & $118(78)$ & $117(77)$ & & $106(68)$ & $110(70)$ & & & & \\
\hline Questionable & $18(12)$ & $22(14)$ & & $31(20)$ & $25(16)$ & & & & \\
\hline Mild & $12(8)$ & $13(9)$ & & $12(8)$ & $18(11)$ & & & & \\
\hline Moderate & $3(2)$ & - & & $7(4)$ & $3(2)$ & & & & \\
\hline Marked & $1(1)$ & - & & $1(1)$ & $1(1)$ & & & & \\
\hline
\end{tabular}

$p$-value given for amisulpride vs. risperidone

${ }^{a}$ Kruskal-Wallis test

${ }^{\mathrm{b} C}$ Cochran-Mantel Haenszel ridit scores

treatment compared with risperidone-treated patients ( $93 \%$ vs. $83 \%$ ). This could be of importance for the compliance of patients as it reflects acceptance of a given treatment.

Both study drugs demonstrated a good global safety profile. However, the incidence of endocrine and sexual symptoms was markedly higher with risperidone than with amisulpride (5.7\% vs. $0.7 \%$ ). During the 6 -month period, significantly fewer amisulpride treated patients presented a weight increase compared with those receiving risperidone. Increase in body weight is recognized to be a significant problem with some antipsychotic medications (Wirshing et al. 1999) and may result in poor compliance.

Neurological safety was excellent with both amisulpride and risperidone. Moreover, the neurological scale scores (SAS, AIMS and BAS) were low at baseline and did not increase during the study, thus indicating that neither drug induced a significant level of extrapyramidal symptoms. These findings are consistent with those from previous studies showing that the atypical antipsychotics are associated with a lower incidence of extrapyramidal symptoms than the typical neuroleptics (Geddes et al. 2000). In addition, both drugs produced low incidences of other adverse events, as indicated by the relatively small numbers of patients that withdrew from treatment for this reason.

The mean risperidone dose with the longest exposure $(6.92 \mathrm{mg} /$ day) used in this study corresponds to the recommended dose range at the time the study was initiated.

The current study confirms previous findings where amisulpride ( $800 \mathrm{mg} /$ day) was compared with risperidone $(8 \mathrm{mg} /$ day $)$ over a short-term, 8 -week period in 228 patients with acute exacerbations of schizophrenia (Peuskens et al. 1999). Amisulpride was at least as effective as risperidone against positive symptoms, with a mean decrease in the BPRS total score of 17.7 and 15.2, respectively. There was a trend in favor of amisulpride against negative symptoms, with a mean decrease in the PANSS negative subscale of 6.9 and 5.3, respectively $(p=.09)$. This previous study also demonstrated the good neurological safety of both study drugs, with no differences between them with regard to the incidence of extrapyramidal symptoms, requirement for antiparkinsonian medication and neurological scale scores. Risperidone was associated with a significant increase in body weight $(1.4 \mathrm{~kg})$ during the study, an effect that was not observed with amisulpride $(p=.026)$. These studies are two of the very few head-to-head comparisons of two atypical antipsychotics.

In conclusion, results confirmed a similar efficacy of amisulpride and risperidone as measured by the PANSS. In addition, the maintenance of the therapeutic effect, response rates, social adaptation, and patient subjective response did show significant advantages of amisulpride over risperidone. Clinical safety was good for both treatments, with a similar incidence of extrapyramidal symptoms, although amisulpride is associated with fewer endocrine and sexual symptoms and significantly less weight gain.

\section{ACKNOWLEDGMENTS}

We gratefully acknowledge the participation of our colleagues from the Amisulpride Study Group: In Austria: M Haushofer, S Kasper, J Stossl. In Belgium: J Baeke, A Boxus, A Denayer, JM Devoitille, G Dierick, J Hannes, J Kusters, C Mertens, J Van Dorpe, B Xhenseval. In Estonia: E Pahn, M Taal. In France: E Belan, D Bonnafoux, M Bourg, M Cazenave, C Claden, JL Colin, P Cullerre, H Hostin, R Julien, L Montet, R Pandelon, M Passamar, J Pon, P Raymondet, G Ruetsch, JC Samuelian, S Schong. In Germany: O Benkert, N Guenther, J Morgner, D Naber, HP Volz. In Hungary: C Banki, G Bartko, I Bitter, I De- 
grell, S Jancsovics, Z Janka, M Trixler. In Latvia: R Andrezina. In the Netherlands: JW Van Hoof. In Slovenia: M Kobal, R Tavcar.

We also wish to acknowledge the Sanofi-Synthelabo Study Team, in particular I. Zieleniuk, M.D., Ph.D., for the statistical analysis and A. Stalla-Bourdillon, M.D., for her help in preparing the manuscript.

This study was sponsored by Sanofi-Synthelabo.

\section{REFERENCES}

American Psychiatric Association (1994): Diagnostic and Statistical Manual of Mental Disorders, 4th ed. Washington, DC, American Psychiatric Association

Andreasen NC (1983): Scale for the Assessment of Negative Symptoms (SANS). Iowa City, University of Iowa.

Barnes TRE (1989): A rating scale for drug-induced akathisia. Br J Psychiat 154:672-673

Arvanitis LA, Miller BG, the Seroquel Trial 13 Study Group (1997): Multiple fixed doses of "Seroquel" (Quetiapine) in patients with acute exacerbation of schizophrenia: a comparison with haloperidol and placebo. Biol Psychiatry 42:233-246

Beasley CM, Sanger T, Satterlee W, Tollefson G, Tran P, Hamilton S, the Olanzapine HGAP Study Group (1996a): Olanzapine versus placebo: results of a doubleblind, fixed-dose olanzapine trial. Psychopharmacology 124:159-167

Beasley CM, Tollefson GD, Tran P, Satterlee W, Sanger T, Hamilton S, the Olanzapine HGAD Study Group (1996b): Olanzapine versus placebo and haloperidol: acute phase results of the North American double-blind olanzapine trial. Neuropsychopharmacology 14:105-118

Bech P, Rafaelsen O (1990): Bech-Rafaelsen Melancholic Scale. In Association for Methodology and Documentation, Collegium Internationale Psychiatriae Scalarum (eds), Rating Scales for Psychiatry. Weinheim, Germany, Beltz Test GmbH

Bell M, Milstein R, Beam-Goulet J, Lysaker P, Cicchetti D (1992): The Positive and Negative Syndrome Scale and the Brief Psychiatric Rating Scale. Reliability, comparability, and predictive validity. J Nerv Ment Dis 180:723-728

Boyer P, Lecrubier Y, Puech AJ, Dewailly J, Aubin F (1995): Treatment of negative symptoms in schizophrenia with amisulpride. Br J Psychiatry 166:68-72

Carman J, Peuskens J, Vangeneugden A (1995): Risperidone in the treatment of negative symptoms of schizophrenia: a meta-analysis. Int Clin Psychopharmacol 10:207-213

Carrière P, Bonhomme D, Lempérière T (2000): Amisulpride has a superior benefit/risk profile to haloperdiol in schizophrenia: results of a multicentre, double blind study (the Amisulpride Study Group). Eur Psychiatry 15:321-329

Chouinard G, Jones B, Remington G, Bloom D, Addington D, MacEwan GW, Labelle A, Beauclair L, Arnott W (1993): A Canadian multicenter placebo-controlled study of fixed doses of risperidone and haloperidol in the treatment of chronic schizophrenic patients. J Clin Psychopharmacol 13:25-40

Colonna L, Saleem P, Dondey-Nouvel L, Rein W (2000): Long-term safety and efficacy of amisulpride in sub- chronic or chronic schizophrenia. Amisulpride Study Group. Int Clin Psychopharmacol 15:13-22

Coulouvrat C, Dondey-Nouvel L (1999): Safety of amisulpride (Solian): a review of 11 clinical studies. Int Clin Psychopharmacol 14:209-218

Danion JM, Rein W, Fleurot O, the Amisulpride Study Group (1999): Improvement of schizophrenic patients with primary negative symptoms treated with amisulpride. Am J Psychiatry 156:610-616

Geddes J, Freemantle N, Harrisson P, Bebbington P for the National Schizophrenia Guideline Development Group (2000): Atypical antipsychotics in the treatment of schizophrenia: systemic overview and meta-regression analysis. Br Med J 321:1371-1376

Hogan TP, Awad AG (1992): Subjective response to neuroleptics and outcome in schizophrenia: a re-examination comparing two measures. Psychological Med 22:347-352

Hoyberg OJ, Fensbo C, Remvig J, Lingjaerde O, Sloth-Nielsen M, Salvesen I (1993): Risperidone versus perphenazine in the treatment of chronic schizophrenic patients with acute exacerbations. Acta Psychiat Scand 88:395-402

Huttunen M, Piepponen T, Rantanen H, Larmo I, Nyholm R, Raitasuo V (1995): Risperidone versus zuclopenthixol in the treatment of acute schizophrenic episodes: a doubleblind parallel-group trial. Acta Psychiat Scand 91:271-277

Janssen PAJ, Niemegeers CJE, Awouters F, Schellekens KHL, Megens AAHP, Meert TF (1988): Pharmacology of risperidone ( $\mathrm{R} 64$ 766), a new antipsychotic with serotonin-S, and dopamine-D2 antagonistic properties. J Pharmacol Exp Ther 244:685-693

Kay SR, Fiszbein A, Opler LA (1987): The Positive and Negative Syndrome Scale (PANSS) for schizophrenia. Schizophr Bull 13:261-276

Leucht S, Pitschel-Walz G, Engel RR, Kissling W (2002): Amisulpride, an unusual "atypical" antipsychotic: a meta-analysis of randomized controlled trials. Am J Psychiatry 159:180-190

Leysen JE, Gommeren W, Eens A, de Chaffoy de Courcelles D, Stoof JC, Janssen PA (1988): The biochemical profile of risperidone, a new antipsychotic. J Pharmacol Exp Ther 247:661-670

Loo H, Poirier-Littre MF, Théron M, Rein W, Fleurot O (1997): Amisulpride versus placebo in the medium-term treatment of the negative symptoms of schizophrenia. Br J Psychiatry 170:18-22

Marder SR, Meibach RC (1994): Risperidone in the treatment of schizophrenia. Am J Psychiatry 151:825-835

Möller H, Boyer P, Fleurot O, Rein W, the PROD-ASLP Study Group (1997): Improvement of acute exacerbations of schizophrenia with amisulpride: a comparison with haloperidol. Psychopharmacol 132:396-401

National Institute of Mental Health (1976a): Clinical Global Impression. In Guy W (ed), ECDEU Assessment Manual for Psychopharmacology Revised Edition. Rockville, MD, National Institute of Mental Health, pp 218-222

National Institute of Mental Health (1976b): AIMS, Abnormal Involuntary Movement Scale. In Guy W (ed), ECDEU Assessment Manual for Psychopharmacology Revised Edition. Rockville, MD, National Institute of Mental Health, pp 534-537 
Paillère-Martinot ML, Lecrubier Y, Martinot JL, Aubin F (1995): Improvement of some schizophrenic deficit symptoms with low doses of amisulpride. Am J Psychiat 152:130-133

Perrault GH, Depoortere R, Morel E, Sanger DJ, Scatton B (1997): Psychopharmacological profile of amisulpride: an antipsychotic drug with presynaptic D2/D3 dopamine receptor antagonist activity and limbic selectivity. J Pharmacol Exp Ther 280:73-82

Peuskens J, Bech P, Möller HJ, Bale R, Fleurot O, Rein W, the Amisulpride Study Group (1999): Amisulpride vs. risperidone in the treatment of acute exacerbations of schizophrenia. Amisulpride study group. Psychiatry Res 88:107-117

Peuskens J, the Risperidone Study Group (1995): Risperidone in the treatment of chronic schizophrenic patients: an international multicentre double-blind parallel-group comparative study versus haloperidol. Br J Psychiat 166: 712-726

Puech A, Fleurot O, Rein W (1998): Amisulpride, an atypical antipsychotic, in the treatment of acute episodes of schizophrenia: a dose-ranging study vs. haloperidol. The Amisulpride Study Group. Acta Psychiatr Scand 98:65-72

Schoemaker H, Claustre Y, Fage D, Rouquier L, Chergui K, Curet O, Oblin A, Gonon F, Carter C, Benavides J, Scatton B (1997): Neurochemical characteristics of amisulpride, an atypical dopamine D2/D3 receptor antagonist with both presynaptic and lymbic selectivity. J Pharmacol Exp Ther 280:83-97
Simpson G, Angus JA (1970): A rating scale for extrapyramidal side effects. Acta Psychiat Scand 45(Suppl 212):11-19

Small JG, Hirsch SR, Arvanitis LA, Miller BG, Link CGG, the Seroquel Study Group (1997): Quetiapine in patients with schizophrenia. Arch Gen Psychiatry 54:549-557

Van Kammen DP, McEvoy KP, Targum SD, Kardatzke D, Seebree TB, the Sertindole Study Group (1996): A randomized, controlled, dose-ranging trial of sertindole in patients with schizophrenia. Psychopharmacology 124:168-175

Van Putten T, May PR (1978): Subjective response as a predictor of outcome in pharmacotherapy. Arch Gen Psychiatry 35:477-480

Wetzel H, Gründer G, Hillert A, Philipp M, Gattaz WF, Sauer H, Adler G, Schröder J, Rein W, Benkert O, the Amisulpride Study Group (1998): Amisulpride versus flupenthixol in schizophrenia with predominantly positive symptomatology - a double-blind controlled study comparing a selective D2-like antagonist to a mixed D1-/D2like antagonist. Psychopharmacol 137:223-232

Wirshing DA, Wirshing WC, Kysar L, Berisford MA, Goldstein D, Pashdag J, Mintz J, Marder SM (1999): Novel antipsychotics: comparison of weight gain liabilities. J Clin Psychiatry 60:358-363

Zimbroff DL, Kane JM, Tamminga CA, Daniel DG, Mack RJ, Wozniak PJ, Sebree TB, Wallin BA, Kashkin KB, the Serdindole Study Group (1997): Controlled, dose-response study of sertindole and haloperidol in the treatment of schizophrenia. Am J Psychiat 154:782-791 